\title{
The Affectivity of Knee and Hip Muscle Strengthening Exercise to Improve Muscle Strength, Balance, Pain, and Functional Activity of People with Osteoarthritis
}

\author{
Djohan Aras ${ }^{1}$, Fatimatuzzahrah Syarif ${ }^{1}$, Natalia Toding Padang ${ }^{1}$, Nurhikmawaty Hasbiah ${ }^{1}$, \\ Herdin Rusli ${ }^{2}$, Ita Rini ${ }^{1}$ \\ ${ }^{1}$ Senior Lecturers of Department of Physiotherapy, Faculty of Nursing, Hasanuddin University, Makassar, \\ ${ }^{2}$ Lecturer Prima Physio Clinic, Makassar, Indonesia
}

\begin{abstract}
Introduction. Osteoarthritis is a common condition that affects elderly people, especially knee osteoarthritis. It can cause pain, muscle weakness, imbalance and low functional activity of elderly people. Knee osteoarthritis not only affects muscles in the knee joint area but also those in the hip joint. To improve symptoms of knee osteoarthritis, strengthening exercise is often conducted only on muscles in the knee joint area, but not muscles in the hip area. This study aimed to compare the effect of strengthening exercise conducted in knee joint muscles only with the strengthening exercise in both knee and hip muscles on pain, strength, balance and functional activity.
\end{abstract}

Method. A pre- and posttest design was chosen as the design of this study. Two groups were formed in this study. Group 1 received strengthening exercise on knee joint muscles only and Group 2 received strengthening exercise on knee joint and hip joint muscles. This study was conducted in Prima Physio Clinic for Group 1 and Tajuddin Chalid Hospital, Makassar for Group 2. On each group, there were 10 subjects with osteoarthritis. The strengthening exercise was conducted for 3 times a week for 4 weeks. The outcome measure used was numeric pain rating scale (NPRS), manual muscle strength (MMT), Berg balance scale (BBS) and Western Ontario McMaster (WOMAC). Manual muscle strength was measured in all major muscles of the joints: iliopsoas, gluteus, tensor fascia lata, quadriceps and hamstring.

Results. The statistical analysis was conducted using Wilcoxon and Mann Whitney tests. In group 1 analysis, pain, balance, functional activity, and all major muscle strengths were found to be a statistically significant difference between baseline and 4 weeks post-exercise. In group 2 analysis, pain, muscle strength, balance, and functional activity were found to be a statistically significant difference $(\mathrm{p}<0.05)$. The comparison between the two groups showed statistically significant differences in all muscle group strength except for hamstring. Pain, balance, functional activity and hamstring strength were not statistically significantly different between the groups.

Conclusion. From the results, we concluded that the strengthening program for both knee and hip muscles is recommended than only to the affected joint muscles.

Keywords: knee osteoarthritis, strengthening exercise, pain, muscle strength, balance, functional activity

\section{Introduction}

In Indonesia, the prevalence of knee osteoarthritis that appears radiologically reaches $15.5 \%$ in men and

\section{Corresponding author:}

Djohan Aras

email address: djohanaras.da@gmail.com
$12.7 \%$ in women aged between $40-60$ years. In the knee osteoarthritis, the affected joints are tibiofemoral and patellofemoral joints depending on the severity of the osteoarthritis ${ }^{1}$. Muscle weakness, balance and postural problem can increase the fall risk among osteoarthritis patients. It can be compounded with the loss of proprioceptive sense of the joints. Sufferer loses the sense of joint position and affects balance ability ${ }^{2}$. 
According to Geenen et $\mathrm{al}^{3}{ }^{3}$, osteoarthritis management aims to reduce pain, increase functional activity, and reduce individual and societal costs. According to a meta-analysis by Fransen et al. ${ }^{4}$, exercise, advice and education for the management of osteoarthritis symptoms are supported with the highest level of evidence. Research has shown that exercise therapy is effective in improving pain and increasing function of people with osteoarthritis ${ }^{5}$.

Research has shown that strengthening exercise can improve muscle strength and increase bone mass ${ }^{6}$. Strengthening exercise on the knee muscles, especially quadriceps, is correlated with the improvement of knee osteoarthritis symptoms. A study showed that quadriceps muscle weakness is common among people with knee osteoarthritis and can become one of the risk factors of knee osteoarthritis ${ }^{7}$. Thus, the quadriceps strengthening exercise becomes the focus of knee osteoarthritis strengthening exercise.

In people with knee osteoarthritis, the addition of hip muscle strengthening exercise to the quadricep strengthening can improve pain, function, walking ability and quality of life compared to quadriceps exercise alone ${ }^{8}$. The previous study showed that the hip and knee exercise group has better improvement of pain and function after 12 weeks of intervention the knee exercise group, especially in patients with patello femoral pain ${ }^{9}$. This study aimed to investigate the effectivity of hip and knee muscle strengthening exercise compared to knee muscle exercise alone in improving function, muscle strength and balance in people with knee osteoarthritis.

According to Kurniawan ${ }^{10}$, the limitation of functional activity of people with stroke is caused by the pain the knee joints. When performing daily activities, knee pain can interfere and make the patients limit their activities to avoid pain. This study aims to investigate the effectivity of knee and hip muscle strengthening on muscle strength, balance, pain and functional activity of people with knee osteoarthritis.

\section{Materials and Method}

Subjects were recruited from Prima Physio Clinic and Dr Tadjuddin Chalid Hospital from March to April 2019. A total of 20 patients were enrolled to participate in this study. Patients were eligible to participate if they were diagnosed with primary or secondary unilateral knee osteoarthritis according to clinical and radiological examination and experienced almost daily knee pain. Patients with other medical problems that can interrupt their participation such as cancer and infectious disease were excluded. Upon agreeing to participate, all patients signed informed consent. Participants were then assigned into two groups according to their recruitment sites. Patients in the Dr Tajuddin Chalid Hospital were assigned to group 1 and received knee muscle strengthening exercise. Patients in the Prima Physio Clinic were assigned to group 2 and received knee and hip muscle strengthening exercise. Both groups were given intervention three times a week for 4 weeks.

The intervention was given in the form of muscle strengthening exercises. In group 1, the strengthening exercise was focused on knee joint muscles, $m$. hamstring and $\mathrm{m}$. quadriceps. The strengthening exercise was conducted by one of the physiotherapists at the study site of group 1. In group 2, in addition to knee joint muscle strengthening exercise, the hip muscles were also targeted including iliopsoas, gluteus and tensor fascia lata. The strengthening exercise was also conducted by one of the physiotherapists at the study site of group 2 . All subjects in both groups were received other standard physiotherapy modalities such as infrared heating, interference, transduction electrical nerve stimulation (TENS), taping, and general exercise.

The outcome measure used was MMT, BBS, NPRS, and WOMAC to measure muscle strength, balance, pain, and functional activity respectively. All measurement was conducted by one of the authors (NTP) who had been trained in using the measurement tools. The measurement was conducted at the Prima Physio Clinic for both groups. The persons who perform the measurement was not aware of the subject assignment as the subjects were told not to reveal their groups, received intervention or study site during measurement. The same person measures all variables and in both groups, at baseline and posttest.

Wilcoxon test was used to compare the pre and posttest in each group. Mann Whitney test was used to compare the difference between groups. Statistical significance was set to 0.05 . Ethical approval for this study was obtained from the Ethics Committee of Health Research, Hasanuddin University Makassar. 


\section{Results}

Table 1. General characteristics of subjects

\begin{tabular}{|c|c|c|c|}
\hline \multicolumn{2}{|c|}{ Characteristic of Samples } & \multirow{2}{*}{\begin{tabular}{|r|} 
Group 1 \\
5 \\
5
\end{tabular}} & \multirow{2}{*}{$\begin{array}{r}\text { Group } 2 \\
4 \\
6\end{array}$} \\
\hline Gender & $\begin{array}{c}\text { Male } \\
\text { Female }\end{array}$ & & \\
\hline Age & $\begin{array}{l}41-50 \\
51-60 \\
61-70 \\
71-80\end{array}$ & $\begin{array}{l}1 \\
2 \\
3 \\
4\end{array}$ & $\begin{array}{l}4 \\
2 \\
2 \\
2\end{array}$ \\
\hline Weight & $\begin{array}{l}44-53 \\
54-62 \\
63-73 \\
74-84\end{array}$ & $\begin{array}{l}2 \\
3 \\
3 \\
2\end{array}$ & $\begin{array}{l}2 \\
4 \\
4 \\
-\end{array}$ \\
\hline Height & $\begin{array}{l}145-155 \\
156-166 \\
167-177 \\
\end{array}$ & $\begin{array}{l}4 \\
2 \\
4\end{array}$ & $\begin{array}{l}4 \\
5 \\
1\end{array}$ \\
\hline Body Mass Index & $\begin{array}{c}\text { Ideal } \\
\text { Overweight } \\
\text { Pre-obesity }\end{array}$ & $\begin{array}{l}4 \\
- \\
6\end{array}$ & $\begin{array}{l}6 \\
1 \\
3\end{array}$ \\
\hline
\end{tabular}

Table 1 shows that the proportion of female and male is similar in both groups. Most subjects are more than 60 years old in both groups. The proportion of the Body Mass Index is relatively even in both groups between ideal and pre-obesity.

Table 2. Effect of the knee and hip muscle strengthening exercise on the improvement of muscle strength, balance, pain and functional activity

\begin{tabular}{|c|c|c|c|c|c|c|}
\hline \multirow{2}{*}{ Variables } & \multicolumn{3}{|c|}{ Group 1} & \multicolumn{3}{|c|}{ Group 2} \\
\hline & Pretest & Posttest & $\mathbf{P}^{*}$ & Pretest & Posttest & $P^{*}$ \\
\hline \multicolumn{7}{|l|}{ MMT } \\
\hline m. Quadriceps & 3 & 4 & 0.002 & 3 & 5 & 0.004 \\
\hline m. Hamstring & 3 & 4 & 0.002 & 3 & 5 & 0.004 \\
\hline m. Iliopsoas & 3 & 4 & 0.046 & 3 & 5 & 0.006 \\
\hline m. Gluteus & 3 & 4 & 0.046 & 3 & 5 & 0.004 \\
\hline m. Tensor fascia latae & 3 & 4 & 0.046 & 3 & 5 & 0.006 \\
\hline BBS & $19.20 \pm 6.663$ & $22.40 \pm 5.542$ & 0.007 & $20.60 \pm 7.321$ & $25.30 \pm 3.620$ & 0.000 \\
\hline NPRS & $7.00 \pm 1.49$ & $5.10 \pm 1.59$ & 0.000 & $7.30 \pm 1.25$ & $3.60 \pm 2.01$ & 0.000 \\
\hline WOMAC & $66.30 \pm 11.52$ & $53.80 \pm 12.13$ & 0.000 & $71.10 \pm 1.25$ & $36.60 \pm 16.39$ & 0.000 \\
\hline
\end{tabular}

*Wilcoxon test 
Table 2 shows that muscle strength in all muscle groups around the hip and knee is improved after the intervention given in both groups. The balance, pain, and functional ability are also improved significantly at the posttest.

Table 3. Differences in the effects between groups on the improvement of muscle strength, balance, pain and functional activity.

\begin{tabular}{|l|c|c|c|}
\hline Variables & Group 1 & Group 2 & P* \\
\hline MMT & & 12.50 & 0.029 \\
\hline m. Quadricep & 8.50 & 12.00 & 0.067 \\
\hline m. Hamstring & 9.00 & 14.00 & 0.005 \\
\hline m. Iliopsoas & 7.00 & 14.30 & 0.002 \\
\hline m. Gluteus & 6.70 & 14.50 & 0.001 \\
\hline m. Tensor fascia latae & 6.50 & 10.90 & 0.578 \\
\hline BBS & 10.10 & 3.70 & 0.519 \\
\hline NPRS & 1.90 & 34.50 & 0.393 \\
\hline WOMAC & 12.50 & & \\
\hline
\end{tabular}

*Mann-Whitney test

Table 3 shows that there is a significant difference in the strength of quadriceps, iliopsoas, gluteus and tensor fascia lata muscles between the groups $(\mathrm{p}<0.05)$. Higher results can be observed in group 2 compared to group 1. Only one muscle group that shows no significant difference between the groups, $\mathrm{m}$. hamstring. However, the higher result can also be observed in group 2 compared to group 1 . There were no significant differences between the groups in terms of balance, pain, and functional activity.

Figure 1 shows that the pain intensity at posttest is improved compared to that at baseline. At baseline, $80 \%$ of subjects in group 1 are in severe pain, while $60 \%$ of group 2 is in moderate pain. At posttest, $50 \%$ of group
1 are in moderate pain compared to $70 \%$ of group 2 are in light pain. This result shows that knee and hip muscle strengthening combination is better in improving pain compared to knee muscle strengthening alone.

Figure 2 shows the improvement of functional activity in both groups. At baseline, $80 \%$ of subjects in group 1 are in heavily dependent compared to $60 \%$ of subjects of group 2 are in moderate dependent. At posttest, $50 \%$ of subjects in group 1 are in moderate dependent compared to $70 \%$ of subjects in group 2 are in light-dependent. This result shows that the combination of knee and hip muscle-strengthening exercise is better in improving functional activity compared to knee muscle strengthening exercise alone.

Table 4. The correlation between pain and functional activity

\begin{tabular}{|l|l|l|l|}
\hline & Variable & $\mathbf{P}$ & Correlation Coefficient \\
\hline Pre-test & \multirow{2}{*}{ Pain and functional activity } & 0.000 & 0.974 \\
\hline Post-test & & 0.000 & 0.841 \\
\hline
\end{tabular}


Table 4 shows that there is a statistically significant correlation $(\mathrm{p}<0.05)$ between pain and functional activity in people with osteoarthritis. The positive correlation was shown in both pretest and posttest measurement of pain and functional activity. According to the correlation coefficient, the correlation is stronger at pretest compared to posttest (0.974 vs. 0.841).
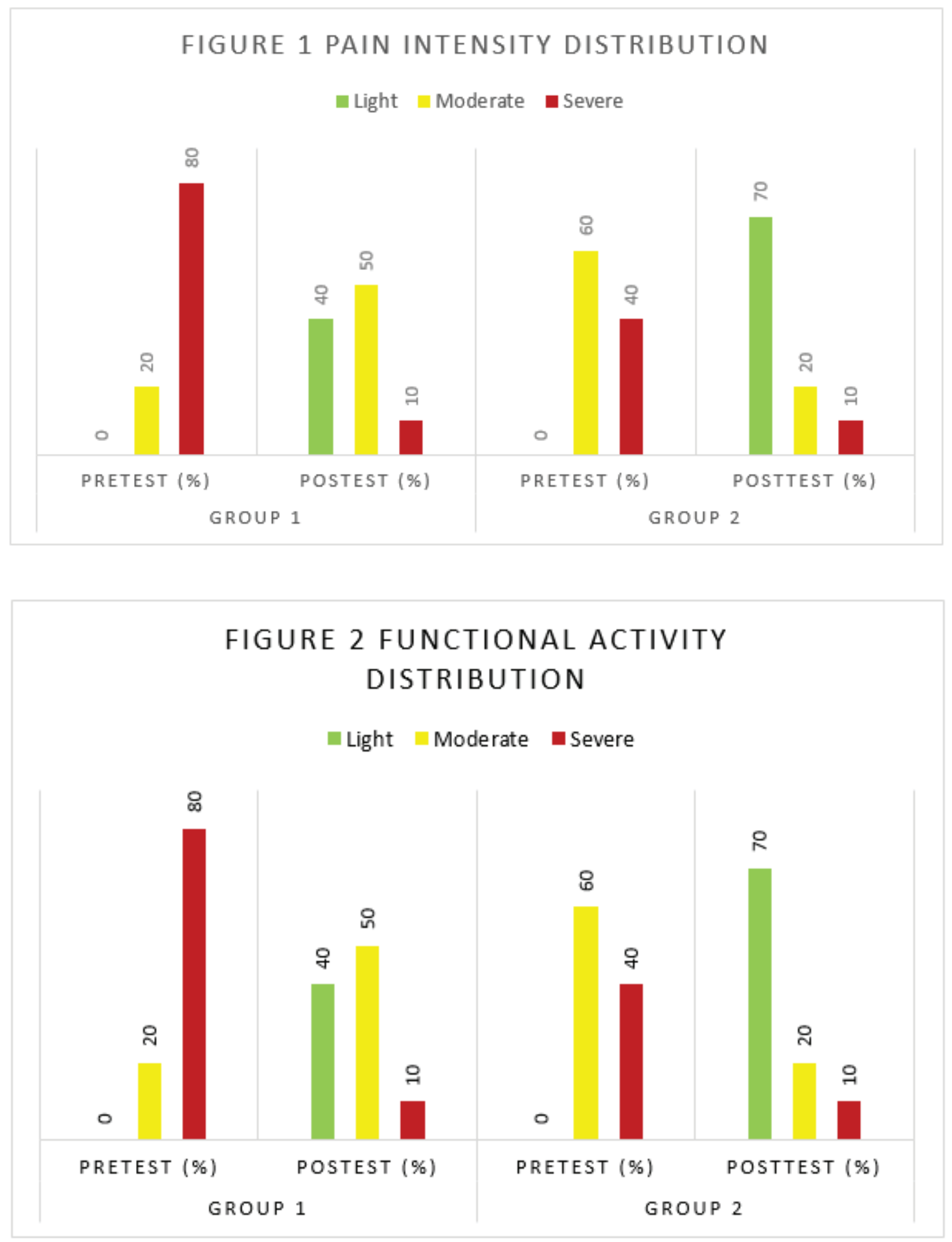


\section{Discussion}

\section{Strength}

The result of this study shows that strengthening hip and knee muscle can improve muscle strengthening significantly. This effect can be explained that the exercise provides neuromuscular adaptation in the long term. Physiologically, the improvement of muscle strength depends on motor unit recruitment. In several weeks of exercise, most of the adoption involves the ability to recruit motor unit that leads to contraction of muscle fibre. As a response to strengthening exercise, neuron activity increase and make actin and myosin number in the muscle fibre also increases. This led to an increase in myofibril hypertrophy and lead to an increase in muscle strength ${ }^{7}$.

This study showed that there is a significant difference in muscle strength between the groups except for $\mathrm{m}$. hamstring. Both $\mathrm{m}$. quadriceps and $\mathrm{m}$. hamstring are knee muscles and was given strengthening exercise in both groups, but only quadriceps showed a significant difference. This means that the additional exercise on hip muscles may affect the quadriceps, but not $\mathrm{m}$. hamstring.

\section{Balance}

This study showed that knee and hip muscle exercise can improve balance in people with knee osteoarthritis. Hall ${ }^{11}$ stated that during muscle contraction, protein synthesis of muscle contractile is faster than its disintegration, which leads to a progressive increase of actin and myosin number inside myofibril. Moreover, the myofibril is multiplying in each muscle fibre to form myofibril hypertrophy. Inside the hypertrophic muscle fibres, the component of the phosphor metabolic system increase, including the ATP and phosphocreatine ${ }^{13}$.

\section{Pain}

This study showed that knee and hip muscle strengthening can improve pain. This result is supported by some previous studies. A study by Kus and Yeldan ${ }^{12}$ show that the strengthening focused on $\mathrm{m}$. quadriceps femoris can reduce pain and improve functional activity in people with knee osteoarthritis. A study by K. L. Bennell et al. ${ }^{14}$ shows that strengthening of adductor and abductor hip muscles for 12 weeks can improve strength, pain, and function in people with medial knee osteoarthritis. A systematic review by Kus and Yeldan ${ }^{12}$ shows that quadriceps muscle strengthening has a positive effect in improving pain and function in people with knee osteoarthritis compared to other treatments that are not included quadriceps muscle strengthening.

\section{Functional Activity}

This study shows that the functional activity of subjects was improved after the application of knee and hip muscle strengthening on people with osteoarthritis. The statistical tests showed that no significant difference in both groups in terms of functional activity improvement. The functional activity in both groups was improved significantly. This can be attributed to the effect of knee and hip muscle strengthening exercise in improving muscle weakness. During repeated exercise, the muscles become hypertrophy and the myofibril increase.

\section{Conclusion}

This study shows that the muscle strengthening on both knee and hip muscles is beneficial in people with knee osteoarthritis in terms of muscle strength, balance, pain, and functional activity. The positive benefit is better showed in the strengthening of muscles in both joints compared to only focus on muscles around affected joints.

Conflict of Interest- The authors certify that they have no affiliation with an organization that may benefit financially or non-financially from the subject discussed in this study. This study is self-funded.

Ethical Clearance- Taken from Hasanuddin University ethical committee

Source of Funding- Self

\section{References}

1. Anggraini, F. D., Santoso, T. B., \& Herawati, I.. Pengaruh Balance Dan Strengthening Exercise Terhadap Aktivitas Fungsional Pada Penderita Osteoarthritis Knee. Universitas Muhammadiyah Surakarta, 2012

2. Bonnin, M., \& Chambat, P. Osteoarthritis of the Knee: Springer Science \& Business Media. 2008

3. Geenen, R., Overman, C. L., Christensen, R., 
Åsenlöf, P., Capela, S., Huisinga, K. L., . . . Pitsillidou, I. A.. EULAR recommendations for the health professional's approach to pain management in inflammatory arthritis and osteoarthritis. Annals of the rheumatic diseases, 2018; 77(6), 797-807.

4. Fransen, M., McConnell, S., Hernandez-Molina, G., \& Reichenbach, S. Exercise for osteoarthritis of the hip. Cochrane Database of Systematic Reviews 2014; (4).

5. Babatunde, O. O., Jordan, J. L., Van der Windt, D. A., Hill, J. C., Foster, N. E., \& Protheroe, J.. Effective treatment options for musculoskeletal pain in primary care: A systematic overview of current evidence. PLoS One, 2017; 12(6), e0178621.

6. Vizniak, N. A.. Evidence-informed Muscle Manual: Professional Health Systems Incorporated. 2018

7. Nugraha, I. A., \& Kambayana, G.. Prinsip Latihan Penderita Osteoartritis. 2017

8. Hislop, A. C., Collins, N. J., Tucker, K., Deasy, M., \& Semciw, A. I. Does adding hip exercises to quadriceps exercises result in superior outcomes in pain, function and quality of life for people with knee osteoarthritis? A systematic review and metaanalysis. British journal of sports medicine, 2019; bjsports-2018-099683.

9. Sahin, H. G., Kunduracilar, Z., Sönmezer, E., Akman, N., Sözer, S., \& Ayas, S. Effects Of Two Different Aquatic Exercises Training On Cardiopulmonary Endurance And Anxiety \&
Depression Scores With Knee Osteoarthritis Patients: 2095 Board\# 247 June 2, 200 PM-330 PM. Medicine \& Science in Sports \& Exercise, 2016; 48(5S), 589.

10. Kurniawan, F.. Hubungan Antara Kualitas Nyeri Dengan Kemampuan Aktivitas Fungsional

Penderita Osteoartritis Lutut. Universitas Muhammadiyah Surakarta, 2015

11. Hall, J. E.. Guyton and Hall textbook of medical physiology e-Book: Elsevier Health Sciences. 2015

12. Kus, G., \& Yeldan, I.. Strengthening the quadriceps femoris muscle versus other knee training programs for the treatment of knee osteoarthritis. Rheumatology International, 2018; 39(2), 203218. doi:10.1007/s00296-018-4199-6

13. Anwar Mallongi, Ezra Limbong, Furqaan Naiem, Hasanuddin Ishak, Syahrul Basri, Muh. Saleh, Aminuddin Syam, Laode Asrul. Health risk analysis of exposure to mercury $(\mathrm{Hg})$ and cyanide $(\mathrm{CN})$ in Kayeli village communities Teluk Kayeli district Buru regency. Enfermería Clínica Volume 30, Supplement 4, June 2020, Pages 427-430

14. Bennell, K. L., Hunt, M. A., Wrigley, T. V., Hunter, D. J., McManus, F. J., Hodges, P. W., Hinman, R. S. Hip strengthening reduces symptoms but not knee load in people with medial knee osteoarthritis and varus malalignment: a randomised controlled trial. Osteoarthritis and Cartilage, 2010; 18(5), 621-628. doi:10.1016/j.joca.2010.01.010 